\title{
Effect of Aerobic and Anaerobic Exercise on Static and Dynamic Balance in Physiotherapy Students
}

\author{
Bhakti Panchal ${ }^{1}$, Dr. Urvashi Sharma ${ }^{2}$, Prof (Dr.) Tushar Palekar ${ }^{3}$ \\ ${ }^{1}$ Physiotherapist, ${ }^{2}$ Assistant Professor, ${ }^{3}$ Professor, Principal
}

Dr. D. Y. Patil College of Physiotherapy, Dr. D.Y. Patil Vidyapeeth, Pimpri, Pune, Maharashtra, India

\begin{abstract}
The aim of the study is to evaluate and compare the effects of aerobic and anaerobic exercise on static and dynamic balance in healthy physiotherapy students. 30 subjects were selected and were divided into two groups $(n=15)$. Assessment was done by stork standing balance test and modified BASS test for static and dynamic balance before the experiment. After completion of the initial balance measurement, group-A subjects were given aerobic exercise which included 15 minutes of Modified Bruce protocol and group-B subjects were given 3 forms of aerobic exercises for 2 weeks alternate days. Post this exercise protocol, balance was reassessed on day 15. Significant changes were found in the pre and post exercise balance scores. Both static and dynamic balance showed improvement but static balance was better improved after aerobic exercise than anaerobic exercise and dynamic balance was better improved after anaerobic exercise than aereobic exercise. Also Aerobic and Anaerobic Exercise showed more improvement in static balance than dynamic balance. Thus, this study concludes that both aerobic and anaerobic exercise showed statistically significant improvement in the static and dynamic balance.
\end{abstract}

Keywords : Static Balance, Dynamic Balance, Aerobic Exercise, Anaerobic Exercise, Physiotherapy Students.

\section{INTRODUCTION}

"The condition in which all the forces acting on the body are balanced such that the center of mass is within the stability limits and boundaries of the base of support(BOS)" Balance is the process of maintaining the center of gravity within the body's base of support ${ }^{1}$ Static balance is ability to maintain postural stability and orientation with center of mass over the base of support when the body is at rest and Dynamic balance is the ability to maintain postural stability and orientation with the center of mass over the base of support while the body parts are in motion. ${ }^{2}$ Maintenance of balance or postural stability requires the individual to maintain center of gravity within the base of support. ${ }^{3}$ Postural control requires correct afferent inputs and efferent outputs from muscles and joints involved ${ }^{4}$ For this an intact sensory information should be obtained from visual, vestibular and somatosensory system. ${ }^{5}$ This information is received by central nervous system which in turn generates appropriate motor actions for balance corrections. ${ }^{6}$

Studies have shown that muscle fatigue and muscle weakness can impair postural stability and can cause sway and put individual at a risk of fall. ${ }^{7,8,9}$

Skeletal muscle gets its energy from Adenosinetriphosphate (ATP). ${ }^{10}$ Only small amount of energy is stored in the cells to carry out few seconds of exercise which means body needs to generate energy in the 
form of ATP. ${ }^{11}$ To restore the limited ATP, chemical reactions add phosphate group back to ADP to generate ATP which is called phosphorylation. If this occurs in the presence of oxygen forming pyruvate as end product then it is called as aerobic metabolism and if it occurs without oxygen forming lactic acid as end product then it is called as anaerobic metabolism or glycolytic metabolism.$^{10}$

ATP-PCR anaerobic systemconsist of adenosinetriphosphate and phosphocreatine. Phosphocreatine breaks to give phosphate and energy with the help of enzyme creatine kinase ${ }^{11}$, which is then used to generate ATP. This system provides energy for the first 3-15 seconds and the power is greatest of all the energy system.

When the activity continues beyond 15 seconds, Glycolytic anaerobic system comes into action. Glycolysis means breakdown of glucose which consist of series of enzymatic reactions. Pyruvic acid is the end product of glycolysis which can then breaks through kreb cycle. This energy system provides energy till 30 seconds of sustained activity through fast glycolysis and at 45 seconds of sustained activity there is a decline in the energy output. Activity beyond this period requires third energy system called Oxidative energy system (Aerobic system $)^{11}$ Glycogen, fats and proteins are utilized according to their availability and intensity of exercise. ATP is resynthesized in the mitochondria and metabolism of oxygen depends upon the number and concentration of mitochondria and cells. It provides the energy from $2^{\text {nd }}$ minute of the sustained activity and it is therefore for the longer duration activity.

Several researches have shown the positive effect of exercise on balance. The purpose of the study is to compare and find the effects of aerobic and anaerobic exercise on the static and dynamic balance as both muscle weakness and fatigue have negative effects on balance in normal healthy individuals. So, it is important to assess balance and find which exercise protocol is more effective in improving the balance.

\section{METHODS AND MATERIAL}

Study location: Dr D Y Patil college of physiotherapy was taken as study place.

Sampling method: Purposeful sampling was done. 30 subjects were selected of age group 18- 25 years. Subjects with recent fracture, subluxation, dislocation, any neurological condition and cardiovascular condition were excluded from this study.

Data collection: 30 subjects were selected which were divided into 2 groups ; Group A (Aerobic exercise group) and Group B(Anaerobic exercise group). Pre exercise static and dynamic balance assessment by stork standing balance test ${ }^{12}$ and Modified BASS test ${ }^{13}$ respectively. Aerobic and anaerobic exercise protocol was given to Group A and Group B respectively for 2 weeks on alternate days. Aerobic protocol included Modified Bruce treadmill protocol ${ }^{14}$ for 15 minutes and anaerobic exercise protocol included single leg vertical jump for 30 seconds continuously followed by 3 minutes rest, immediately after rest subjects would perform single leg hop for 30 seconds. After rest period of 3 minutes subject would perform depth jump for 30 seconds $^{15}$. On day 15, subjects were reassessed for static and dynamic balance with stork standing balance test and Modified BASS test.

Data was analyzed using "primer" statistical package software. 30 physiotherapy students were included in the study.The data was entered into excel spread sheet, tabulated and subjected to statistical analysis. 
Table 1 : Effect of aerobic exercise on static balance

\begin{tabular}{|l|l|l|l|l|l|}
\hline $\begin{array}{l}\text { Stork } \\
\text { standing } \\
\text { balance } \\
\text { test }\end{array}$ & Mean & $\begin{array}{l}\text { Mean } \\
\text { difference }\end{array}$ & $\begin{array}{l}\text { Standard } \\
\text { deviation }\end{array}$ & $\begin{array}{l}\text { T } \\
\text { value }\end{array}$ & $\begin{array}{l}\mathrm{P} \\
\text { value }\end{array}$ \\
\hline Pre & 8.267 & -6.667 & 2.086 & - & 0.001 \\
\cline { 1 - 2 } post & 14.93 & & 3.474 & 5.953 & \\
\hline
\end{tabular}

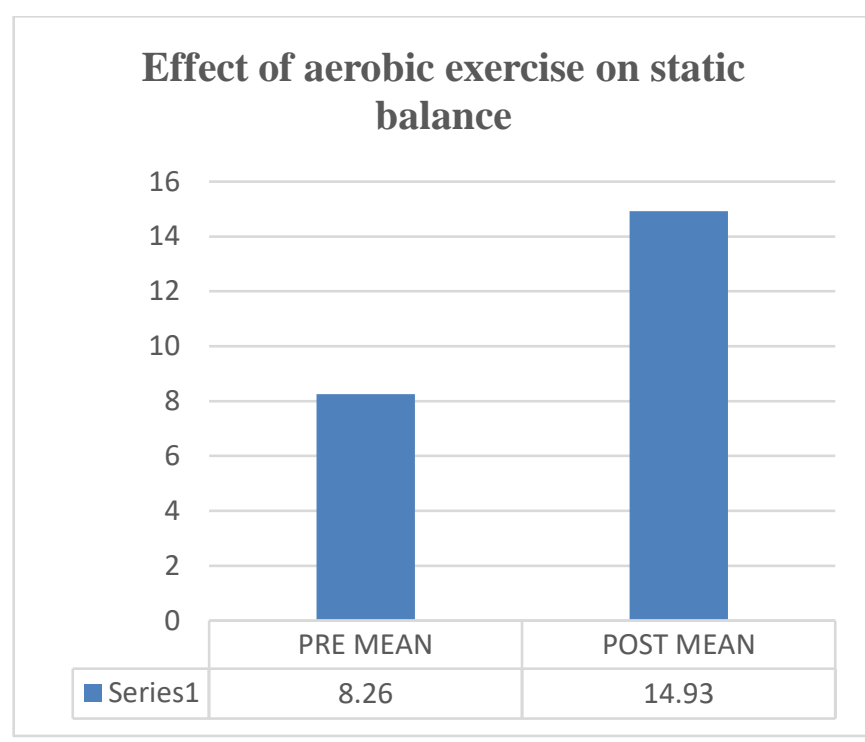

Figure 1 : Effect of aerobic exercise on static balance

Interpretation: Table 1 and figure 1 shows pre and post mean of static balance of the aerobic group. The Pre-mean of static balance was 8.267 which changed to 14.93 in post with mean difference of -6.667 . PreStandard Deviation was 2.086 which changed to 3.474. The data was analyzed using paired $t$ test which gave $t$ value $=-5.953$ and $p=0.001$. Thus, the study is statistically significant. And shows significant improvement in static balance.

Table 2 : Effect of aerobic exercise on dynamic balance

\begin{tabular}{|l|l|l|l|l|l|}
\hline MODIF & ME & MEAN & STAND & T & P \\
IED & AN & $\begin{array}{l}\text { DIFFERE } \\
\text { BASS } \\
\text { TEST }\end{array}$ & & $\begin{array}{l}\text { NCE } \\
\text { DEVIAT } \\
\text { ION }\end{array}$ & VAL \\
UE & VAL \\
\hline PRE & 83.2 & -3.867 & 9.982 & - & 0.00 \\
& 7 & & & 6.05 & 1 \\
\hline
\end{tabular}

\begin{tabular}{|l|l|l|l|l|l|}
\hline POST & $\begin{array}{l}87.1 \\
3\end{array}$ & & 9.687 & 2 & \\
\hline
\end{tabular}

\section{Effect of aerobic exercise on dynamic balance}

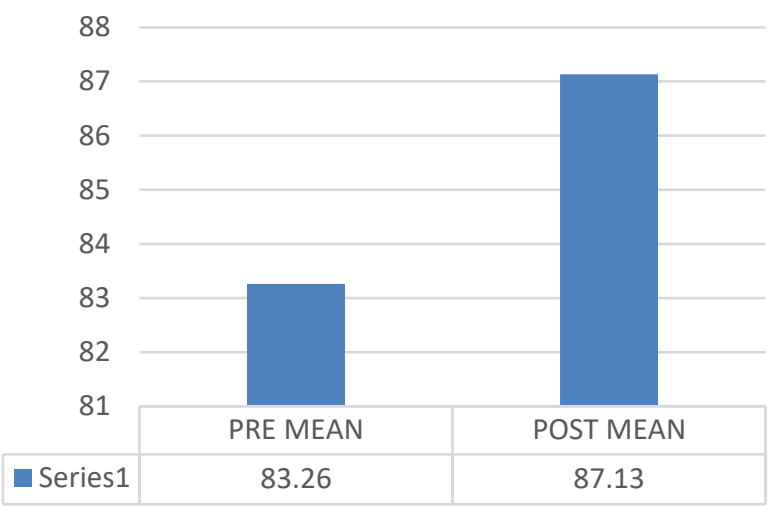

Figure 2 : Effect of aerobic exercise on dynamic balance

Interpretation: Interpretation: Table 2 and figure2 shows pre and post mean of static balance of the aerobic group. The Pre-mean of dynamic balance was 83.27 which changed to 87.13 in post with mean difference of 87.13. Pre-Standard Deviation was 9.982 which changed to 9.687 . The data was analyzed using paired $t$ test which gave $t$ value $=-6.052$ and $\mathrm{p}=0.001$. Thus, the study is statistically significant. And shows significant improvement in dynamic balance.

Table 3 : Effect of anaerobic exercise on static balance

\begin{tabular}{|c|c|c|c|c|c|}
\hline STORK & $\mathrm{ME}$ & MEAN & STAND & $\mathrm{T}$ & $\mathrm{P}$ \\
\hline STAND & $\mathrm{AN}$ & DIFFERE & ARD & VAL & VAL \\
\hline ING & & NCE & DEVIAT & UE & UE \\
\hline BALAN & & & ION & & \\
\hline $\mathrm{CE}$ & & & & & \\
\hline TEST & & & & & \\
\hline PRE & 8.6 & \multirow[t]{3}{*}{-8.267} & 1.404 & \multirow{3}{*}{$\begin{array}{l}- \\
16.4 \\
66\end{array}$} & \multirow{3}{*}{$\begin{array}{l}0.00 \\
1\end{array}$} \\
\hline \multirow[t]{2}{*}{ POST } & 16.8 & & 1.767 & & \\
\hline & 7 & & & & \\
\hline
\end{tabular}




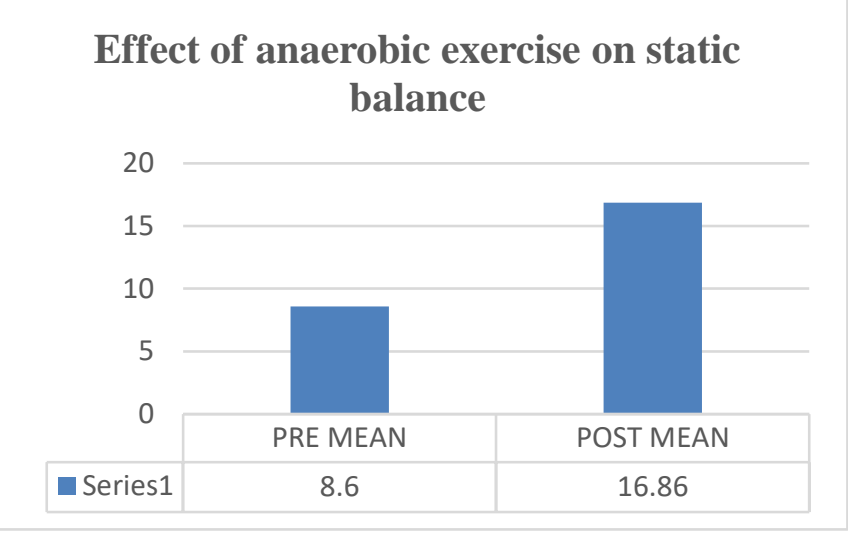

Figure 3: Effect of anaerobic exercise on static balance

Interpretation: Table 3 and Graph 3 shows pre and post mean of static balance of the aerobic group. The Pre-mean of static balance was 8.6 which changed to 16.87 in post with mean difference of -8.267 . PreStandard Deviation was 1.404 which changed to 1.767. The data was analyzed using paired $t$ test which gave $t$ value $=-16.466$ and $p=0.001$. Thus, the study is statistically significant And shows improvement in static balance.

Table 4: Effect of anaerobic exercise on dynamic balance

\begin{tabular}{|c|c|c|c|c|c|}
\hline $\begin{array}{l}\text { MODIF } \\
\text { IED } \\
\text { BASS } \\
\text { TEST }\end{array}$ & $\begin{array}{l}\text { ME } \\
\text { AN }\end{array}$ & $\begin{array}{l}\text { MEAN } \\
\text { DIFFERE } \\
\text { NCE }\end{array}$ & $\begin{array}{l}\text { STAND } \\
\text { ARD } \\
\text { DEVIAT } \\
\text { ION }\end{array}$ & $\begin{array}{l}\text { T } \\
\text { VAL } \\
\text { UE }\end{array}$ & $\begin{array}{l}\text { P } \\
\text { VAL } \\
\text { UE }\end{array}$ \\
\hline PRE & $\begin{array}{l}89.5 \\
3\end{array}$ & \multirow[t]{2}{*}{-5.267} & 4.34 & & \multirow[t]{2}{*}{$\begin{array}{l}0.00 \\
1\end{array}$} \\
\hline POST & 94.8 & & 4.443 & 50 & \\
\hline
\end{tabular}

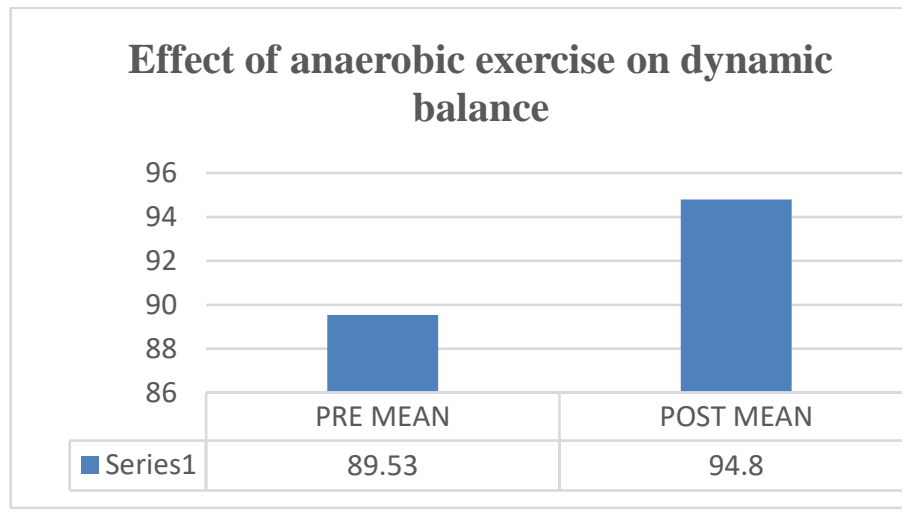

Figure 4: Effect of anaerobic exercise on dynamic balance

Interpretation: Table 4 and Graph 4 shows pre and post mean of static balance of the aerobic group. The Pre-mean of dynamic balance was 89.53 which changed to 94.8 in post with mean difference of 5.267. Pre-Standard Deviation was 4.34 which changed to 4.443 . The data was analyzed using paired $\mathrm{t}$ test which gave $\mathrm{t}$ value $=-19.750$ and $\mathrm{p}=0.001$. Thus, the study is statistically significant.And shows improvement in dynamic balance.

Table 5: Comparison of the effect of aerobic and anaerobic exercise on static balance

\begin{tabular}{|c|c|c|c|c|c|}
\hline STATIC & $\mathrm{ME}$ & MEAN & STAND & $\mathrm{T}$ & $\mathrm{P}$ \\
\hline BALAN & $\mathrm{AN}$ & DIFFER & ARD & VAL & VAL \\
\hline $\begin{array}{l}\text { CE IN } \\
\text { GROUP: }\end{array}$ & & ENCE & $\begin{array}{l}\text { DEVIA } \\
\text { TION }\end{array}$ & UE & UE \\
\hline AEROBI & 9.99 & \multirow[t]{4}{*}{1.667} & 2.187 & \multirow{4}{*}{$\begin{array}{l}2.20 \\
6\end{array}$} & \multirow{4}{*}{$\begin{array}{l}0.03 \\
6\end{array}$} \\
\hline C & 3 & & & & \\
\hline ANAER & 8.26 & & 1.944 & & \\
\hline OBIC & 7 & & & & \\
\hline
\end{tabular}

Interpretation: Table 5 shows Mean of the difference in static balance in aerobic and anaerobic group which is 9.993 in aerobic group and 8.267 in anaerobic group. The mean difference of aerobic and anaerobic group is 1.667 . the data was analyzed using $t$ test which gives $t=2.206$ and $p=0.036$ which is significant. This indicates aerobic group showed more improvement in static balance than anerobic group. 
Comparison of the effect of aerobic and a exercise on static balance

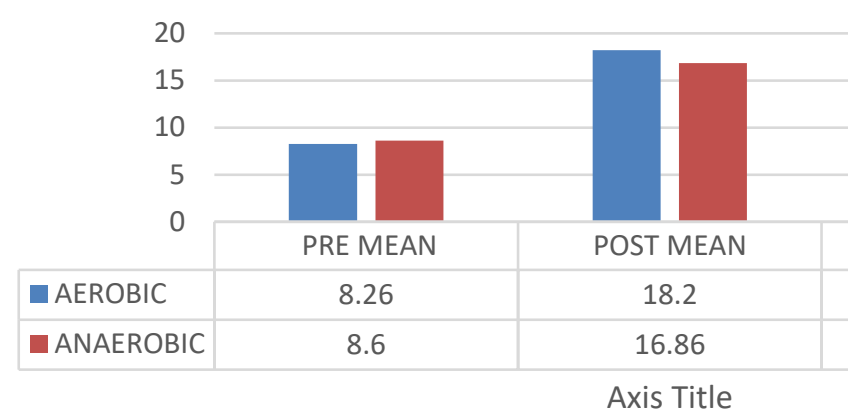

AEROBIC ANAEROBIC

Figure 5: Comparison of the effect of aerobic and anaerobic exercise on static balance

Interpretation: Graph 5 shows pre and post mean of static balance after aerobic and anaerobic exercise.The pre-mean of static balance after aerobic exercise is 8.26 which changed to 18.2 and the premean of static balance after anaerobic exercise is 8.6 which changed to 16.86 . The mean difference of aerobic group is 9.94 and of anaerobic group is 8.26which shows aerobic group showed more improvement in static balance than anaerobic group Table 6: Comparison of the effect of aerobic and anaerobic exercise on dynamic balance.

\begin{tabular}{|l|l|l|l|l|l|}
\hline DYNAM & ME & MEAN & STAND & T & P \\
IC & AN & DIFFER & ARD & VAL & VAL \\
BALAN & & ENCE & $\begin{array}{l}\text { DEVIA } \\
\text { CION IN }\end{array}$ & UE & UE \\
GROUP: & & & TION & \\
\cline { 1 - 4 } $\begin{array}{l}\text { AEROBI } \\
\text { C }\end{array}$ & 7.86 & -1.4 & 2.475 & - & 0.05 \\
\cline { 1 - 2 } & 5.26 & & 1.033 & 2 & 3 \\
OBIC & 7 & & & & \\
\hline
\end{tabular}

Interpretation: Table 6 shows Mean of the difference in dynamic balance in aerobic and anaerobic group which is 3.867 in aerobic group and 5.267 in anaerobic group. The mean difference of aerobic and anaerobic group is -1.4. The data was analyzed using $t$ test which gives $t=-2.022$ and $p=0.053$ which is not significant. This indicates anaerobic group showed more improvement in dynamic balance than aerobic group.

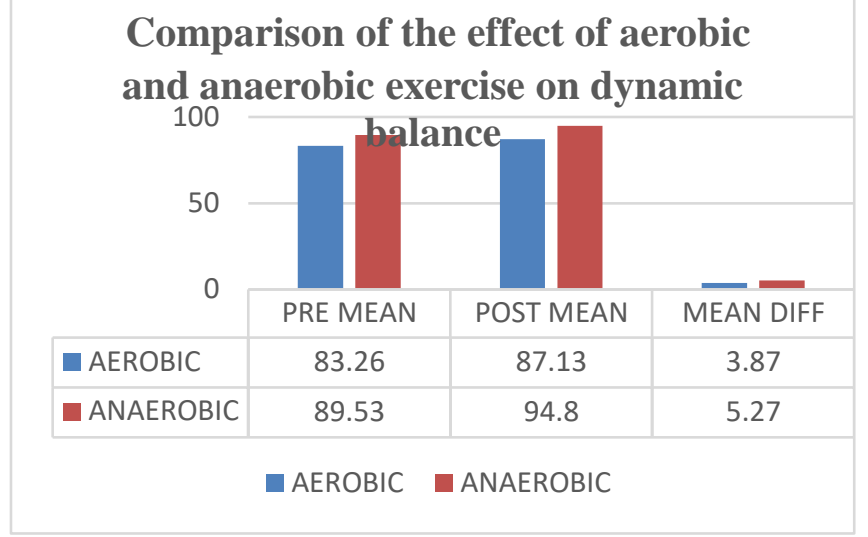

Figure 6: Comparison of the effect of aerobic and anaerobic exercise on dynamic balanceInterpretation Graph 6 shows pre and post mean of dynamic balance after aerobic and anaerobic exercise. The pre-mean of dynamic balance after aerobic exercise is 83.26 which changed to 87.13 and the pre-mean of dynamic balance after anaerobic exercise is 89.53 which changed to 94.8 . The mean difference of aerobic group is 3.87 and of anaerobic group is 5.27. which shows anaerobic group showed more improvement in dynamic balance than aerobic group.

\section{DISCUSSION}

The aim of the study was to compare the effect of aerobic and anaerobic exercise on static and dynamic balance in physiotherapy students. At the end of the study it was determined that the ability to maintain the balance was improved in both aerobic and anaerobic group. The results were significant with $\mathrm{p}$ value 0.001 . Also, Static balance was more improved after aerobic exercise than after anaerobic exercise with mean difference of 1.667 and $p$ value 0.036 which is statistically significant and Dynamic balance 
was more improved after anaerobic exercise than after aerobic exercise with mean difference of -1.4 and $p$ value 0.053 which is not significant.

Similar to this study, Eslamian et al(2005) performed a study on effects of aerobic versus strengthening exercises on improvement of balance, bone mineral density and quality of life in post-menopausal women with osteoporosis which stated increased muscle force, balance and improved quality of life after 6 months exercise program. ${ }^{12}$ Another study performed by Kiani et al (2018) on effects of aerobic exercises on balance in diabetic neuropathy patients showed significant improvement in balance when aerobic exercises were given with the traditional balance training. As it affects the progression of neuropathy 14 Jakobsen et al(2011) showed reduction in COP path length and postural sway after 12 weeks of high intensity interval running.

Contradicting to the above mention studies, Mathew et al (2016) performed a study on effect of high intensity cycling training on postural sway during standing under rested and fatigued conditions in healthy young adults showed that after 3 and 6 weeks of high intensity cycling training did not improve the postural stability during the rested conditions. However, 6 week of high intensity training showed improvement in maintaining balance in the fatigued condition. Similar to this study, Hassonlovei et al (2014) reported that 6 weeks of moderate intensity cycling training did not show any effect on anteroposterior sway during rested condition for which the reason stated was that the cycling does not involve body movement as whole which train the balance ability.

As both the groups showed improved postural stability by eliciting neuromuscular changes such as muscle strength, firing rate and synchronization.A combination of both aerobic and anaerobic exercise protocol is recommended for those who need to improve balance, specifically, aerobic exercise to improve static balance and anaerobic exercise to improve dynamic balance. Also, aerobic and anaerobic Exercise showed more improvement in static balance than dynamic balance)

\section{REFERENCES}

[1]. Cote KP, Brunet ME.Effect of pronated and supinated foot on static and dynamic postural stability.Journal of athletic training 2005;40(1)41-47.

[2]. Arnold BL, Motte DL, Linens S and Ross S. Ankle instability is Associated with balance impairments: A Meta-Analysis. Med sci. sports exerc.2009.41(5)1048-1062.

[3]. Adlerton AK, Moritz U. Does calf-muscle fatigue affect standing balance? Scand J Med Sci sports 1996;6(4)211-5.

[4]. Gurfinkel V. S., Ivanenko YP, Levik YS, and Babakova IA. Kinesthetic reference for human orthograde posture. Neuroscience. 1995;68(1)229-243.

[5]. Horak FB, Macpherson JM. Postural orientation and equilibrium. In:Rowell LB, Sheherd JT, editors. Handbook of physiology.

[6]. Diener and Dichgans, 1988.

[7]. Vuillerme N, Forestier N, Nougier V. Attentional demands and postural sway: The effect of the calf muscle fatigue. 2002: med. Sci. sports exercise, 34(12)1907-1912.

[8]. Iverson, BD, Gossman MR, Shadddeau SA, and Turner ME Jr. Balance performance, force production, and activity levels in noninstitutional men 60-90 years of age. Phys. Ther: 70(6)348-355, 1990.

[9]. Wolfson L., Judge J, Whipple R, and king M. Strength is a major factor in balance, gait, and 
the occurrence of fall. A biol. Sci. med. Sci. 50, 64-67, 1995.

[10]. McArdle WD, Katch FI and Katch VL. Essentials of Exercise Physiology: 2nd Edition Philadelphia, PA: Lippincott Williams \& Wilkins. 2000.

[11]. Wilmore JH and Costill DL. Physiology of Sport and Exercise: 3rd Edition. Champaign, IL: Human Kinetics. 2005.

[12]. Johnson BL, Nelson JK. Practical measurements for evaluation in physical education. 4th edition. Minneapolis: Burgess, 1979.

[13]. Johnson and Nelson: Modified BASS test:Practical measurements for evaluation in physical education 4 th ed.

[14]. Walters Kluwer. ACSM'S Guidelines for exercise testing and prescription.. 10th ed. ISBN-1-4963-3907-X. Pg 121.

[15]. G. Gregory Haff, N. Travis Triplett.Essentials of strength training and conditioning. 3rd ed. ISBN- 978-1-4925-0162-6

\section{Cite this article as :}

Bhakti Panchal, Urvashi Sharma, Dr. Tushar Palekar, "Effect of Aerobic and Anaerobic Exercise on Static and Dynamic Balance in Physiotherapy Students", International Journal of Scientific Research in Science and Technology (IJSRST), Online ISSN : 2395-602X, Print ISSN : 2395-6011, Volume 6 Issue 2, pp. 495-501, March-April 2019. Available at doi : https://doi.org/10.32628/IJSRST1196291 Journal URL : http://ijsrst.com/IJSRST1196291 